\title{
Patients' views of antidepressants: from first experiences to becoming expert
}

\author{
Peter Schofield, Ann Crosland, Waquas Waheed, Saadia Aseem, \\ Linda Gask, Annie Wallace, April Dickens and André Tylee
}

\begin{abstract}
Background

The majority of patients discontinue antidepressant treatment earlier than prescribed. The factors behind this and the influences on patients' choices about whether to take medication remain poorly understood. Aim

To explore factors that influence patients' decisions about taking antidepressant medication.

Design of study

Qualitative interview study.

Setting

Interviews were conducted across three sites: London, East Lancashire, and North East England.

\section{Method}

Semi-structured interviews were conducted with a purposive sample of 65 primary care patients who were prescribed antidepressants in the past year for depression or mixed anxiety/depression.

Results

Participants described their first course of antidepressants as typically occurring when they had 'hit rock bottom', having exhausted all other possibilities; therefore, there was little sense of a positive choice at this stage. There would typically follow a period of experimentation where it was usual to stop and restart medication, often several times. Ultimately, these recurring cycles lead to participants becoming more expert about their condition and better able to make an informed decision about medication. For younger participants, recovery typically remained a goal, although for older people there was often an acceptance that their condition, and medication use, would be long term.
\end{abstract}

\section{Conclusion}

Participants' accounts demonstrated how they could become expert at managing their condition through a process of trial and error.

\section{Keywords}

antidepressants; depression; ethnicity; primary health care; qualitative research.

\section{INTRODUCTION}

Despite the recent growth in the numbers of antidepressants prescribed by GPs, many patients with depression discontinue medication early. ${ }^{1,2}$ From previous qualitative studies it is apparent that the reasons why people stop taking antidepressants are complex, ${ }^{3,4}$ and may include: the symptoms of depression improving or becoming worse, the experience of side-effects or adverse events, perceived stigma, peer pressure, adverse media stories, pre-existing beliefs, difficulties with cost and the availability of care, and preference for other interventions, particularly counselling. ${ }^{5,6}$

There are relatively few studies concentrating on patients' accounts, in their own words, of their experiences of treatment, and more qualitative research in this area has been called for. ${ }^{4}$ While studies have tended to concentrate on clinical

P Schofield, BSc, MSc, PhD, senior research fellow, Department of Primary Care and Public Health Sciences, Division of Health and Social Care Research; A Tylee, MD FRCGP MRCPsych, academic director, Mood Anxiety and Personality Clinical Academic Group, Kings Health Partners, Kings College London and Head, Section of Primary Care Mental Health, Institute of Psychiatry, Kings College London, London. A Crosland, PhD, BA(Hons), RGN, professor; A Wallace, BA, BSc, MSc, project director public health curriculum development; A Dickens, PhD student, Faculty of Applied Sciences, University of Sunderland, Sunderland. W Waheed, MRCPsych, professor, academic consultant psychiatrist; S Aseem, MPA, research assistant; L Gask, PhD, FRCPsych, FRCGP, professor of primary care psychiatry and honorary consultant psychiatrist, University of Manchester and Salford Primary Care Trust, Manchester Academic Health Sciences Centre, Manchester.

Address for correspondence

Peter Schofield, King's College London, Department of Primary Care and Public Health Sciences, 7th Floor, Capital House, 42 Weston Street, London, SE1 3QD.

E-mail: peter.1.schofield@kcl.ac.uk

Submitted: 22 February 2010; Editor's response: 30 March 2010; final acceptance: 15 September 2010.

(c)British Journal of General Practice

This is the full-length article (published online 28 Mar 2011) of an abridged version published in print. Cite this article as: Br J Gen Pract 2011; DOI: 10.3399/bjgp1 1X567045. 
factors, it has been argued there is a need for further research to account for the complex family, social, and ethnic factors that influence decisions.

Previous research in the UK has been small scale in terms of English-speaking participants in single localities. The aim of this study was to explore and compare the factors that influence patients' decisions about their treatment across three localities in England, chosen for their diversity and including one ethnic minority (South Asian) participant group.

\section{METHOD}

\section{Study design}

This was a qualitative study comprising a series of semi-structured interviews with patients across three different sites: London, East Lancashire, and North East England. The London sample was recruited from five GP practices chosen to reflect a broad range of socioculturally and ethnically mixed areas in south and west London. The East Lancashire sample was recruited from six GP practices in semi-rural areas comprising a predominantly South Asian population. The North East England sample was recruited across seven GP practices chosen to reflect a range of urban/rural and affluent/deprived communities.

\section{Participants}

Participants had been prescribed antidepressants for depression or mixed anxiety and depression in the past year. A purposive sampling design was used to recruit a broad range of participants reflecting the sex, age, ethnicity, and socioeconomic background of patients using antidepressants across the local practice populations in each of the sites. A total of 61 participants were recruited, comprising 23 in the London sample, 18 in East Lancashire, and 20 in North East England (Table 1).

\section{Study procedure}

Eligible patients received a letter from their GP, inviting them to take part in the study. Attached to this was a study information sheet, consent form, and stamped addressed envelope, which they were asked to complete and return if they wished to take part. Those who wished to participate were then contacted by the research team and interviews were arranged. Participants were offered a £10 shopping voucher in return for giving up their time. The study received formal ethical approval from the London Multicentre Research Ethics Committee, which covered each centre. Due to difficulty in recruitment in East Lancashire, further permission was obtained for a member of the practice team to follow up the letter with a telephone call, which increased recruitment at this site.

\section{How this fits in}

Few studies have looked at the use of antidepressants from patients

perspectives. This study was novel in adopting a multisite qualitative approach

and, in common with previous studies, confirmed the importance of: the

experience of side-effects, fears of symptoms returning, fear of dependency,

the views of friends and family, fear of stigma, and a preference for alternative

treatments. The study shows how a process of experimentation, typically

involving stopping and starting medication, can lead to patients becoming

expert in managing their condition and adds to the growing body of literature

demonstrating the importance of self-management as a strategy for dealing

with mental disorder.

Interviews took place between December 2006 and January 2008. These were carried out either in the patient's own home or elsewhere, depending on the patient's preference. Each interview lasted for approximately 1 hour and followed a topic guide based on the study aims and reflecting themes derived from the existing literature. This was further developed after a preliminary phase comprising the first five interviews, where initial findings and preliminary analysis were used to focus the guide, and this was then further refined at subsequent analysis meetings.

\section{Analysis method}

Interview recordings were transcribed and, for the East Lancashire sample, interviews with Urdu speakers were translated into English. Analysis followed the constant comparison method: ${ }^{8,9}$ that is, transcripts were initially coded, by researchers at each centre, using categories derived from the topic guide as a starting point, and subsequently new codes were added where these did not fully reflect participants' experiences. This local analysis was used to inform the selection of participants in an iterative way.

Codes from each site were then further evaluated and refined with regard to the data as a whole, both within and across each centre, until a saturation point was reached where no new codes were necessary. To facilitate this process, regular analysis meetings were conducted with researchers from each of the three centres. Emerging themes were discussed in detail, identifying both commonalities and themes that differentiated between the three settings.

\section{RESULTS}

From the large amount of data collected in this study, it was apparent that participants talked about a wide range of factors that helped shape their decisions about whether or not to take, and continue with, antidepressant medication. Table 1 shows how diverse the sample was in terms of sample 
Table 1. Participant characteristics.

\begin{tabular}{|c|c|c|c|c|c|c|c|c|c|}
\hline \multirow[t]{2}{*}{ Ref } & \multicolumn{3}{|c|}{ London } & \multicolumn{3}{|c|}{ East Lancashire } & \multicolumn{3}{|c|}{ North East England } \\
\hline & Sex & Age, years & Ethnicity & Sex & Age, years & Ethnicity & Sex & Age, years & Ethnicity \\
\hline 1 & Female & 64 & White & Female & 35 & Pakistani & Male & 34 & White British \\
\hline 2 & Female & 55 & White & Female & 36 & Pakistani & Female & 29 & White British \\
\hline 3 & Male & 60 & White & Female & 38 & Pakistani & Male & 69 & White British \\
\hline 4 & Male & 35 & White & Female & 25 & Pakistani-British born & Female & 60 & White British \\
\hline 5 & Male & 50 & White & Female & 50 & Pakistani & Female & 55 & White British \\
\hline 6 & Female & 27 & White & Female & 33 & Pakistani-British born & Female & 69 & White British \\
\hline 7 & Female & 27 & African-Caribbean & Female & 45 & Pakistani & Male & 56 & White British \\
\hline 8 & Female & 42 & African-Caribbean & Male & 35 & Pakistani-British born & Female & 34 & White British \\
\hline 9 & Male & 35 & White & Female & 41 & Bangladeshi & Female & 58 & White British \\
\hline 10 & Male & 43 & White & Female & 60 & Pakistani & Male & 33 & White British \\
\hline 11 & Male & 40 & White & Female & 73 & Pakistani & Female & 57 & White British \\
\hline 12 & Male & 61 & White & Female & 40 & Pakistani & Female & 29 & White British \\
\hline 13 & Male & 49 & White & Female & 35 & Pakistani-British born & Female & 32 & White British \\
\hline 14 & Female & 66 & White & Female & 50 & Pakistani & Male & 35 & White British \\
\hline 16 & Female & 78 & White & Female & 34 & Pakistani-British born & Female & 34 & White British \\
\hline 17 & Female & 44 & White & Male & 45 & Bangladeshi & Male & 76 & White British \\
\hline 18 & Female & 69 & White & Female & 54 & Pakistani & Male & 62 & White British \\
\hline 19 & Female & 40 & African & & & & Female & 52 & White British \\
\hline 20 & Male & 46 & White & & & & Female & 83 & White British \\
\hline 21 & Female & 95 & White & & & & & & \\
\hline 22 & Female & 71 & White & & & & & & \\
\hline 23 & Female & 64 & White & & & & & & \\
\hline
\end{tabular}

characteristics, and Table 2 provides a brief summary to show the range of medication experience. This article focuses on how an understanding of the experience of medication over time, along with sex and age factors, can help start to explain the complex decision-making processes that patients experience and the trade-offs they make when deciding whether to start or continue taking antidepressants.

\section{First experiences}

For the majority of participants this was not their first episode of depression or their first prescription for antidepressants. Some had experienced intermittent episodes of depression over a long period of time; for others it was a long-term problem, and for only a minority the current episode was their first. All could recount their first experiences of seeking help for depression.

The common thread running through their accounts included a sense of having 'hit rock bottom' and being desperate before seeking help from their GP, at which point they describe a desire for anything to relieve their symptoms and help them get back to normal:

'I think we both felt that I needed something, I was having a bit of a crisis and I needed something quite quickly.' (London 18)

Many reported going in to the initial GP consultation with reservations about antidepressants, primarily because of fear of addiction or stigma, and a general reluctance to take any medication:

'But I didn't know if antidepressants were the right things for us because you hear so much about them. Because like once you get on to them you get addicted to them and like I have heard loads of like bad reports.' (North East England 2)

'Yeah I think definitely [stigma was an issue], which is why I avoided taking antidepressants for about 15 years when I quite possibly should have been.' (London 10)

However, few reported feeling able to contribute to the decision-making process at this point, as it was too difficult to take in information. All participants in this study accepted the initial prescription; some willingly, others less so:

'Oh I've always got a choice but at the time I, I wanted help so anything they would have suggested.' (London 12)

At the time of the first episode most people expected to get better, and often antidepressants were seen as a short-term measure to help them achieve this: 
'It gets you over that hurdle.’ (London 16)

Having received this first prescription, some reported that they continued to take the medication exactly as prescribed, with older patients and some Asian women being most likely to follow their GPs' advice:

'At that time I would take anything, I just took what the doctor's given me.' (East Lancashire 3)

However, not all were so accepting: some reported experiencing side-effects quite early on, and choosing among going back to the GP to get the prescription changed, trying to stop their medication themselves, or continuing despite the side-effects. At this stage in the process, despite their concerns, most continued with their medication and waited to return to normal.

\section{Experiences over time}

Over time, many people reported experimenting with their medication by either stopping it altogether or altering their doses:

'When they gave me the tablets, after about 2 months it doesn't take straight away to go, I changed the tablets and everything.' (East Lancashire 14)

'I play around with my medication. I change it, take some in the morning, some in the evening.' (North East England 7)

This decision was influenced by a wide range of factors including: a general motivation to not take medication over the long term; concerns about the way that antidepressants challenged their sense of self, for example, by making them feel numb and abnormal; fear of addiction; side-effects; cost; stigma; and pressure from other people, especially family and friends, to stop taking medication:

'To me, they are almost like a mental anaesthetic and no more feeling, emotions, you know.' (North East England 3)

'I don't like to be bound down by the thought that I might have to take the medication for the rest of my life.' (London 12)

'Well my family told me to stop taking them, they weren't happy about it.' (East Lancashire 1)

While those who had gone through this process of experimentation told the story in different ways and suggested different reasons for their behaviour, they all followed a similar process of trial and error.

Some stopped altogether, others stopped and then restarted of their own accord, and others stopped and substituted antidepressants with alcohol or illicit drugs. Those in the latter group were most likely to be younger males. The end result was that a minority coped, but others reached a point of crisis before returning to the GP for help:

I was still struggling with whether or not I was going to take them I just didn't want to take them and on some days when I was like feeling like oh I'm sliding back down I would take one and maybe for that week and then afterwards and it was a bit of a rollercoaster really.' (London 9)

This process of trial and error was most commonly reported by those who also spoke of dissatisfaction with the help and advice given by their GP. Those who continued taking medication were more likely to report a good relationship with their GP, which was commonly characterised by the GP being a good listener, or because they were happy to hand over decision making to the GPs. Some in this latter group appeared quite passive in their acceptance of a ' $\mathrm{Dr}$ knows best' approach, and commonly feared getting back to 'rock bottom' so accepted the doctors' advice unquestioningly. This view was most commonly found in older people, and in particular older women, from each of the three study sites:

'Oh yes, it's no good going to a doctor and ask saying, "What do you think? What do I need?" and then not doing what they say. It's a waste of their time and mine.' (London 17)

For those who went through this process of trial and error, their experience appeared to help them to learn more about their illness, so that as they went through cycles of depression they started to make more conscious decisions about their medication. They would recognise signs of depression earlier with each cycle and so seek help earlier in the process:

'But I think I've learned a great deal over the years about depression and also about

Table 2. Patterns of antidepressant use.

\begin{tabular}{lccccc} 
& Stopped & $\begin{array}{c}\text { Intending } \\
\text { to stop }\end{array}$ & Cyclical use & $\begin{array}{c}\text { Long-term } \\
\text { use }\end{array}$ & $\begin{array}{c}\text { Total } \\
\text { participants }\end{array}$ \\
\hline London & 5 & 7 & 5 & 6 & 23 \\
\hline East Lancashire & 2 & 2 & 6 & 8 & 18 \\
\hline North East England & 4 & 2 & 6 & 8 & 20 \\
\hline
\end{tabular}


recognising signs within myself from the depression point of view.' (North East England 5)

They also tended to try other therapies and became more informed about the alternatives and so started to make decisions about medication within the wider context of managing depression.

\section{Becoming expert}

'Because you hear a lot of people talk about depression at work and things and you look at them and think. No that's not how it was. And you know I'm really clued up now like really clued up.' (North East England 2)

Through recurring cycles of depression and antidepressant taking, many patients reported that their decision making changed as they became more expert about their condition. They learned to trade off the risks and the benefits, for example, putting up with the side-effects versus the fear of becoming depressed again:

'When I know I'm depressed I will take it because I know I need it, but now I'm alright I'm okay for the time being, the biggest side-effect is every time when I stop I become a lot worse than what I was to begin with. But every time I'm a lot worse than the first time.' (East Lancashire 15)

Participants viewed antidepressants as either helping them in their own right or as a temporary solution while waiting for talking therapies. The majority still sought to get better rather than to just manage their problems. This was especially true among younger participants, whereas older participants, and those with more continuous problems, altered their expectations over time and sought more stability in their lives rather than total recovery. At the extreme of this continuum, patients described their depression as a long-term condition or disability that they anticipated would be with them for the rest of their lives:

'... with what I identify as a disability. That's all it is, you know. I mean the only problem is that if I did lose my leg, people would see it.' (North East England 7)

Older participants were also more likely than younger patients to have to deal with comorbid conditions and depression, which therefore became part of a bigger health picture that affected the decisions taken. The trade off here was between treatments for different illnesses rather than a trade off of risks and benefits. This was often influenced by the way that GPs responded to their problems, that is, whether they discussed depression as part of the whole picture or focused on physical illness.

Many participants continued to question the longterm nature of medication, but still viewed this as being necessary at difficult times. Knowing when to take medication at these times was one important area where they had developed an expertise:

'I have had episodes where l've gone back on to them. I seem to come off for a while. I mean there have been quite a few occasions where I've gone back on them for 6 to 8 months ... I feel as if I know now when I'm going to start to go back down again and I get sort of signs and symptoms ...' (North East England 13)

Expertise did not just mean making informed decisions about antidepressants within the context of other therapeutic approaches or other illnesses, it could also mean making a decision to take medication over the long term. While this latter approach could suggest a more passive response to illness, for some this was because their experience of trying to reduce their medication had led them to believe their problems were not going to go away. As they saw it, acceptance of long-term medication could mean that they could get on with their lives:

'If it ended up being, I ended up having to take them for the rest of my life, otherwise I'm going to go crashing down again, then fair enough you know.' (London 9)

This approach was often combined with a reluctance to reduce medication or come off it altogether, even when encouraged to do so by the GP:

'Matter of fact, if the doctor said to me, "Well we're going to try and take you off", I'd say, "No you're not".' (London 14)

However, for others this was far from a positive choice. Becoming an expert meant becoming resigned to taking medication long term even though this was not a choice they were happy with:

'I read all the leaflets what she used to give me but I don't know ... I think I know it all myself now, I feel like I have had it for that long. It's just coping with it; it's that bit I can't do really unless I am on my tablets. I would like to turn round I must admit and not be on them and know how to deal with it myself but I don't think that will ever happen.' (North East England 14) 


\section{DISCUSSION}

\section{Summary of main findings}

Other studies have identified myriad factors that influence concordance with medication, ${ }^{1-6,10}$ while what is new here is the recognition that these factors can be seen as part of an overarching process whereby people become expert in their decision making. From the initial consultation (often dominated by the fear of stigma and dependency and concerns about the way that antidepressants challenge the patient's sense of self) through to subsequent episodes (when the risks of sideeffects are balanced against the longer-term benefits), the story that emerged in this study is one of patients becoming expert through a process of trial and error. Thus, many people who initially accept a prescription of antidepressants are motivated not to take their medication and will try to stop at some point.

Most participants in this study described their depression as cyclical, and through repeated cycles of depression and a process of trial and error many patients had become more informed decision makers and had learned to trade off risks and benefits. Not everyone developed this expertise in the same way, or over the same time period; however, all told the story of how they make more informed decisions as they go through repeated cycles of depression and as they try to reduce or stop medication either on their own or with GP support.

\section{Strengths and limitations of the study}

A strength of the study was that it combined the use of in-depth interviews with a multisite design that provided a range of contexts and participant characteristics. The study successfully recruited patients with a range of experiences of depression, as well as people from diverse backgrounds. This allows for comparison across study sites and across social groups.

However, as only people who have had a prescription of antidepressants in the last year were sought, it is unlikely that all views and experiences of antidepressants have been captured; in particular the views of people who have rejected or opted out of taking antidepressants are not represented here. While the study may have benefited from more specific inclusion criteria, including people with depression who refused medication, given the difficulties faced with recruiting subjects on an 'optin' basis and the limited resources at the researchers' disposal, the researchers opted for more general criteria. Also the results presented here relate to only one key theme derived from these data. These factors should therefore be taken into account when interpreting the results.

\section{Comparison with existing literature}

Other authors have considered how a diagnosis of depression has a negative impact on a person's sense of self. ${ }^{11,12}$ This study expands this evidence by suggesting that the fear of being labelled in this way, and the resultant stigma mean that many people with depression initially seek help only when they have reached a crisis point and are thus often not in a position to make an informed decision about antidepressant medication. Many of the factors subsequently highlighted by patients here as influencing their decisions about medication have also been reported elsewhere, ${ }^{13-17}$ and with evidence that patients' preferences change over time. ${ }^{3}$ What the present study shows is that these individual factors fit into a changing picture of patients' experiences and will assume greater or lesser importance as patients become expert in decision making over time.

A recent meta-synthesis by Pound et al suggested that patients generally do not like taking medication for a range of complaints, and the findings here indicate that the same is true for antidepressants. ${ }^{4}$ The findings reported here suggest that while actions such as changing the dose or trying to stop medication may result in negative consequences in the short term, in the longer term they may lead to more informed decision making and could indicate patients taking control of their situation. This could be an indicator of their preparedness for self-management as advocated by others. ${ }^{12,18-20}$

\section{Implications for clinical practice and future research}

GPs need to recognise that patients are not motivated to take medication over the long term, especially medication such as antidepressants that may challenge patients' sense of self. Furthermore, patients' motivation and illness framework can vary over time. Therefore, open discussion about medication may need to be revisited with patients at regular intervals, with the recognition that many will have tried to stop their medication at some point. People develop expertise at different rates and the challenge for GPs is to help them achieve this with minimum harm and maximum information.

Future studies are needed to address how patients can best be encouraged to take a more self-determining role in their use of medication, in collaboration with their GP, as it is unclear whether those who develop expertise through experimentation with their medication would develop this more quickly with GP support, or whether taking control of this themselves is an essential part of the process. 


\section{Funding body}

The study was funded by an unrestricted grant from Servier UK. It was an independent piece of work and does not necessarily reflect the views of the funding body.

\section{Ethics committee}

Multicentre ethical approval was granted by Guy's Ethics Committee (Main LREC reference number 06/Q0704/145).

\section{Competing interests}

AT is partly funded by the National Institute for Health and Research (NIHR) Mental Health Biomedical Research Centre at the Institute of Psychiatry and South London and Maudsley Foundation Trust at King's Health Partners Academic Health Sciences Centre.

\section{Acknowledgements}

We would like to thank all the participants who gave up their time and shared their experiences with us and also the participating practices for their help with the study.

\section{Discuss this article}

Contribute and read comments about this article on the Discussion Forum: http://www.rcgp.org.uk/bjgp-discuss

\section{REFERENCES}

1. Pampallona S, Bollini P, Tibaldi G, et al. Patient adherence in the treatment of depression. Br J Psychiatry 2002; 180: 104-109.

2. Mitchell AJ. Adherence behaviour with psychotropic medication is a form of self-medication. Med Hypotheses 2007; 68(1): 12-21.

3. Malpass A, Shaw A, Sharp D, et al. 'Medication career' or 'mora career'? The two sides of managing antidepressants: a metaethnography of patients' experience of antidepressants. Soc Sci Med 2009: 68(1): 154-168.

4. Pound P, Britten N, Morgan M, et al. Resisting medicines: a synthesis of qualitative studies of medicine taking. Soc Sci Med 2005; 61(1): 133-155.

5. Dwight-Johnson M, Sherbourne CD, Liao D, Wells KB. Treatment preferences among depressed primary care patients. J Gen Intern Med 2000; 15(8): 527-534.

6. Priest RG, Vize C, Roberts A, et al. Lay people's attitudes to treatment of depression: results of opinion poll for Defeat Depression Campaign just before its launch. BMJ 1996; 313(7061): 858-859.
7. Demyttenaere K. Compliance during treatment with antidepressants. J Affect Disord 1997; 43(1): 27-39.

8. Glaser BG, Strauss AL. The discovery of grounded theory: strategies for qualitative research. Chicago: Aldine, 1967.

9. Strauss A, Corbin J. Basics of qualitative research: techniques and procedures for developing grounded theory. Thousand Oaks: Sage Publications, 1998.

10. Hunot VM, Horne R, Leese MN, et al. A cohort study of adherence to antidepressants in primary care: the influence of antidepressant concerns and treatment preferences. Prim Care Companion J Clin Psychiatry 2007; 9(2): 91-99.

11. Karp DA. Taking Anti-depressant medications: resistance, trial commitment, conversion, disenchantment. Qual Sociol 1993; 16(4): 337 .

12. Stevenson F, Knudsen P. Discourses of agency and the search for the authentic self: the case of mood-modifying medicines. Soc Sci Med 2008; 66(1): 170-181.

13. Grime J, Pollock K. Patients' ambivalence about taking antidepressants: a qualitative study. Pharm J 2003; 271(7270): 516-519.

14. Knudsen P, Hansen E, Traulsen J. Perceptions of young women using SSRI antidepressants - a reclassification of stigma. Int $J$ Pharm Pract 2002; 10(4): 243-252.

15. North D, Davis P, Powell A. Patient responses to benzodiazepine medication: a typology of adaptive repertoires developed by longterm users. Sociol Health Illn 1995; 17(5): 632.

16. Smith F, Francis SA, Rowley E. Group interviews with people taking long-term medication: comparing the perspectives of people with arthritis, respiratory disease and mental health problems. Int J Pharm Pract 2000; 8(2): 88-96.

17. Usher K. Taking neuroleptic medications as the treatment for schizophrenia: a phenomenological study. Aust N Z J Ment Health Nurs 2001; 10(3): 145-155.

18. Johnston O, Kumar S, Kendall K, et al. Qualitative study of depression management in primary care: GP and patient goals, and the value of listening. Br J Gen Pract 2007; 57(544): 872-879.

19. Khan N, Bower P, Rogers A, et al. Guided self-help in primary care mental health: meta-synthesis of qualitative studies of patient experience. Br J Psychiatry 2007; 191: 206-211.

20. Conrad P. The meaning of medications: another look at compliance. Soc Sci Med 1985; 20(1): 29-37. 